\title{
Eficiência de sabonetes comerciais antissépticos contra bactérias patogênicas e
}

\section{análise dos rótulos}

\author{
Efficiency of commercial antiseptic soaps against pathogenic bacteria and labels analysis \\ Eficiencia de jabones comerciales antisépticos contra bactérias patógenas y análisis de etiquetas
}

Recebido: 21/01/2021 | Revisado: 31/01/2021 | Aceito: 05/02/2021 | Publicado: 10/02/2021

\author{
Jeisa Patricia Leitzke \\ ORCID: https://orcid.org/0000-0002-3702-8459 \\ Universidade Paranaense, Brasil \\ E-mail: jeisa.patricia@hotmail.com \\ Tatiany Alves Nierri \\ ORCID: https://orcid.org/0000-0001-5775-133X \\ Universidade Paranaense, Brasil \\ E-mail: tatianierri@hotmail.com \\ Jaqueline Hoscheid \\ ORCID: https://orcid.org/0000-0002-0020-9002 \\ Universidade Paranaense, Brasil \\ E-mail: jaquelinehoscheid@prof.unipar.br \\ Nathielle Miranda \\ ORCID: https://orcid.org/0000-0002-9692-9636 \\ Universidade Paranaense, Brasil \\ E-mail: nathielle@ prof.unipar.br
}

\begin{abstract}
Resumo
Os sabonetes em barra com ação antisséptica são destinados à limpeza de resíduos presentes no corpo, sua utilização tem crescido significativamente em decorrência da preocupação da população com determinadas doenças causadas por contaminação microbiológica. Com isso, têm surgido no mercado diferentes marcas de sabonetes garantindo a eliminação de $99,9 \%$ das bactérias. O objetivo deste estudo foi realizar a análise comparativa do $\mathrm{pH}$, atividade antibacteriana e rótulos de 5 diferentes marcas de sabonetes antibacterianos em barra, identificados como A, B, C D e E. Realizou-se a determinação do $\mathrm{pH}$ com auxílio de pHmetro digital, e na análise microbiológica utilizou-se a metodologia de disco difusão, com o intuito de observar a presença ou ausência da multiplicação das bactérias Streptococcus pyogenes, Klebsiella pneumoniae, Pseudomonas aeruginosa, Staphylococcus epidermidis, Staphylococcus aureus e Escherichia coli frente aos diferentes sabonetes testados. Durante a análise da rotulagem dos sabonetes foi avaliada a presença do requisito "composição", exigido pela resolução vigente. Nos testes realizados constatou-se que o pH de todas as marcas testadas encontraram-se fora dos parâmetros estabelecidos. Na análise microbiológica observou-se que apenas a marca $\mathrm{E}$, demonstrou efeito antisséptico frente às bactérias testadas. Os demais sabonetes apresentaram menor e até mesmo nenhum potencial de inibição do crescimento desses microrganismos. Os produtos analisados neste estudo apresentam em suas formulações duas substâncias ativas, o triclosan e o triclocarban, porém os mesmos podem ser nocivos para a saúde humana e meio ambiente, e induzirem a resistência bacteriana, por isso, alguns países já proibiram o uso destes ativos. Segundo os resultados obtidos é possível concluir que os rótulos presentes das embalagens destas diferentes marcas analisadas estão em desacordo com o estabelecido pelos fabricantes.
\end{abstract}

Palavras-chave: Higiene; Sabonete; Antibacterianos; Triclosan.

\begin{abstract}
Bar soaps with antiseptic action are intended for cleaning residues present in the body, their use has grown significantly due to the population's concern about certain diseases caused by microbiological contamination. With this, different brands of soaps have appeared on the market, guaranteeing the elimination of $99.9 \%$ of bacteria. The aim of this study was to perform a comparative analysis of $\mathrm{pH}$, antibacterial activity and labels of 5 different brands of antibacterial bar soaps, identified as $\mathrm{A}, \mathrm{B}, \mathrm{C}, \mathrm{D}$ and $\mathrm{E}$. The $\mathrm{pH}$ was determined with the aid of a digital $\mathrm{pH}$ meter, and in the microbiological analysis, the disk diffusion methodology was used in order to observe the presence or absence of the multiplication of the bacteria Streptococcus pyogenes, Klebsiella pneumoniae, Pseudomonas aeruginosa, Staphylococcus epidermidis, Staphylococcus aureus and Escherichia coli against the different soaps tested. During the analysis of the labeling of the soaps, the presence of the "composition" requirement required by the current resolution was evaluated. In the tests carried out it was found that the $\mathrm{pH}$ of all tested brands were outside the established parameters. In the microbiological analysis, it was observed that only the E mark showed an antiseptic effect against
\end{abstract}


the tested bacteria. The other soaps showed less and even no potential to inhibit the growth of these microorganisms. The products analyzed in this study present in their formulations two active substances, triclosan and triclocarban, however they can be harmful to human health and the environment, and induce bacterial resistance, therefore, some countries have already banned the use of these assets. According to the results obtained, it is possible to conclude that the labels present on the packaging of these different brands analyzed are at variance with that established by the manufacturers.

Keywords: Hygiene; Soap; Antibacterials; Triclosan.

\section{Resumen}

Los jabones en barra con acción antiséptica están destinados a la limpieza de residuos presentes en el organismo, su uso ha crecido significativamente debido a la preocupación de la población por determinadas enfermedades provocadas por la contaminación microbiológica. Con ello han aparecido en el mercado diferentes marcas de jabones, garantizando la eliminación del 99,9\% de las bacterias. El objetivo de este estudio fue realizar un análisis comparativo de $\mathrm{pH}$, actividad antibacteriana y etiquetas de 5 marcas diferentes de jabones en barra antibacterianos, identificado como A, B, C, D y E. El pH se determinó con la ayuda de un pHmetro digital, y en el análisis microbiológico se utilizó la metodología de difusión en disco para observar la presencia o ausencia de la multiplicación de las bacterias Streptococcus pyogenes, Klebsiella pneumoniae, Pseudomonas aeruginosa, Staphylococcus epidermidis, Staphylococcus aureus y Escherichia coli frente a los diferentes jabones ensayados. Durante el análisis del etiquetado de los jabones se evaluó la presencia del requisito de "composición" exigido por la resolución actual. En las pruebas realizadas se encontró que el $\mathrm{pH}$ de todas las marcas probadas estaba fuera de los parámetros establecidos. En el análisis microbiológico, se observó que solo la marca E mostró un efecto antiséptico contra las bacterias probadas. Los otros jabones mostraron menos e incluso ningún potencial para inhibir el crecimiento de estos microorganismos. Los productos analizados en este estudio presentan en sus formulaciones dos principios activos, triclosán y triclocarbán, sin embargo pueden ser nocivos para la salud humana y el medio ambiente, e inducir resistencias bacterianas, por ello, algunos países ya han prohibido el uso de estos activos. De acuerdo con los resultados obtenidos, es posible concluir que las etiquetas presentes en los envases de estas diferentes marcas analizadas están en desacuerdo con lo establecido por los fabricantes.

Palabras clave: Higiene; Jabone; Antibacterianos; Triclosan.

\section{Introdução}

As práticas higiênicas são realizadas mundialmente pela população para evitar a contaminação, principalmente devido a grande quantidade de microrganismos e bactérias presentes em todas as áreas (Odonkor, et al., 2019). No mercado mundial, são encontradas diversas formulações e composições de substâncias destinadas à eliminação das sujidades e microrganismos presentes na superfície do corpo humano, porém os sabonetes em barra possuem maior destaque por serem utilizados em larga escala pela população (Júnior, 2011).

A pele é o maior órgão do corpo humano e por ser um tecido de superfície, torna-se reservatório para diversos microrganismos, e estes podem ser transferidos de um local para outro, por meio do contato direto ou indireto, sendo as mãos a principal via de transmissão (Marisco, Salgado \& Santos, 2019).

Microrganismos residentes e transitórios habitam a pele humana normal, sendo estes principalmente bactérias Grampositivas e Gram-negativas. A microbiota residente é uma população de microrganismos geralmente não patogênicos, presentes em grande quantidade sobre a pele, e após serem removidos, reconstituem-se facilmente. Apesar da microbiota residente ser relativamente constante, fatores ambientais, como clima e exposição à radiação ultravioleta, e também fatores do hospedeiro, como idade, sexo e raça, podem ter influência na quantidade e nos tipos de microrganismos que compõem a sua microbiota (Two et al., 2016).

A microbiota residente está presente sobre as camadas mais profundas da pele, sendo assim, possui maior resistência frente à tentativa de remoção apenas através de água e sabonete (Anvisa, 2009).

Já a microbiota transitória está presente temporariamente, sendo influenciada pelo meio ambiente, ou seja, sua recomposição vai depender de fatores externos, não se reconstituindo tão facilmente. Esses microrganismos apresentam um menor tempo de sobrevivência, porém maior potencial patogênico e são facilmente transmitidos por contato (Martins, 2014). 
Devido à produção de ácido láctico, o pH da pele é levemente acidificado $(4,6$ - 5,8), tornando-se um dos principais mecanismos de proteção contra fungos e bactérias (Leonardi, et al., 2002), conferindo à superfície cutânea um "manto ácido cutâneo", o qual é constantemente desafiado por agressores externos como a poluição, mudanças de temperatura e a exposição de produtos químicos (Eucerin, 2016).

Os sabonetes são substâncias compostas principalmente de uma mistura de ácidos graxos e sais alcalinos com propriedades detergentes, podendo ser perfumados e coloridos, com consistência e tamanho variável (Anvisa, 2007). Espera-se que apresentem características como saponificação, molhagem, penetração, capacidade de diminuir a tensão superficial, capacidade de controlar depósitos minerais, possuam pH próximo ao fisiológico da pele, tenham baixo custo e sejam seguros para os manipuladores (Andrade, 2008).

As moléculas de sabão têm propriedades polares e não polares, permitindo a solubilização das sujidades e sua remoção pela lavagem. Consequentemente, os sabonetes comuns não matam necessariamente bactérias e vírus, mas simplesmente ajudam a lavá-los da pele (Rangel, 2017).

Com o intuito de reduzir e prevenir problemas relacionados às bactérias presentes sobre a pele humana podem ser utilizados os sabonetes antibacterianos, também conhecidos como antimicrobianos ou antissépticos. Esses possuem em sua composição substâncias biocidas, que inativam os microrganismos e os biocidas que matam o organismo alvo (Martins, 2014).

Os sabonetes antibacterianos em barra, através do seu uso diário, são destinados à limpeza de resíduos presentes no corpo, como remoção de sujeiras, maus cheiros, assepsia das mãos, limpeza do rosto e do corpo. Além disso, são responsáveis pela morte de bactérias presentes normalmente no corpo humano e assim agem prevenindo doenças e infecções de pele (Freire, et al., 2012; Draelos, 2018).

Visto que, no mercado mundial encontram-se inúmeras variedades de agentes químicos fornecidos com a promessa de eliminar 99,9\% das bactérias presentes na pele humana, influenciando assim, na prevenção, contra determinadas doenças adquiridas por contaminação microbiológica, o presente estudo tem como principal objetivo realizar a análise comparativa do $\mathrm{pH}$, atividade antibacteriana e rótulos de 5 (cinco) diferentes marcas de sabonetes antibacterianos em barra, de baixo custo comercial, disponíveis em supermercados e farmácias do Município de Toledo, Paraná, Brasil.

\section{Metodologia}

As análises foram realizadas nos Laboratórios de Microbiologia e Farmacotécnica da Universidade Paranaense Unidade de Toledo, Paraná, Brasil. Selecionou-se, aleatoriamente, 5 (cinco) diferentes marcas de sabonetes antibacterianos de baixo custo comercial adquiridos em supermercados e farmácias locais. A escolha dessas marcas se deu devido a facilidade de serem encontrados em farmácias e supermercados da região, pelo baixo custo dos mesmos, e por serem comumente utilizados pela população nos cuidados de higiene diários. Por questões éticas, os nomes das marcas dos produtos testados não foram descritos, sendo identificados com as letras A, B, C, D e E.

\subsection{Avaliação da rotulagem}

Segundo a RDC $\mathrm{n}^{\circ}$ 07, de 10 de fevereiro de 2015 (Brasil, 2015), os cosméticos de grau 2, classe em que enquadramse os sabonetes antibacterianos, devem conter a composição descrita na embalagem primária ou secundária quando presente.

O estudo foi de caráter descritivo, exploratório e qualitativo, por meio da análise da rotulagem dos sabonetes antibacterianos, onde foi avaliada a presença do requisito "composição" exigido pela resolução vigente. 


\subsection{Método de disco-difusão}

Os sabonetes antibacterianos foram avaliados quanto à sua atividade antibacteriana diante das bactérias Grampositivas Staphylococcus aureus (ATCC 25923), Staphylococcus epidermidis (ATCC 12228) e Streptococcus pyogenes (ATCC 19615), e Gram-negativas Escherichia coli (ATCC 25922), Pseudomonas aeruginosa (ATCC 27853) e Klebsiella pneumoniae. Essas bactérias foram selecionadas por serem encontradas na pele humana, além disso, em algumas embalagens os próprios sabonetes traziam a informação para qual bactéria apresentava "99,9\%" de eficácia.

As culturas dos microrganismos foram mantidas através de passagens diárias para tubos contendo caldo infusão cérebro coração (BHI) e incubadas em estufa a $36^{\circ} \mathrm{C}$.

Para a avaliação foram preparadas suspensões de bactérias em salina com turbidez comparada à escala de McFarland $10^{5} \mathrm{UFC} / \mathrm{mL}$, utilizando-se de culturas bacterianas com 24 horas de crescimento. Em seguida com auxílio de swab, realizou-se a semeadura das suspensões bacterianas padronizadas sobre placas de Petri contendo o Ágar. Para S. pyogenes utilizou-se Ágar sangue e o Ágar Muller Hinton foi utilizado para as demais bactérias testadas.

Foram colocados 7 (sete) discos de papel sobre a semeadura de bactérias de interesse, entre eles, um disco contendo $20 \mu \mathrm{L}$ (microlitros) apenas do solvente utilizado para diluição (caldo Muller Hinton) e outro disco contendo o antibiótico padrão específico para a bactéria testada naquela placa. Para bactérias Gram-negativas utilizou-se o antibiótico tetraciclina e para bactérias Gram-positivas o antibiótico ampicilina. Nos demais discos utilizou-se $20 \mu \mathrm{L}$ de cada marca de sabonete diluído (NCCLS, 2003).

Optou-se por diluir os sabonetes para que pudessem se difundir mais facilmente nos discos colocados sobre o meio de cultura e assim agir sobre as bactérias utilizadas no teste. Para a dissolução, pesou-se 5 gramas de cada sabonete e adicionou-se $50 \mathrm{~mL}$ de água destilada, atingindo-se a concentração corresponde a $100 \mathrm{mg} / \mathrm{mL}$. A mistura foi levada a aquecimento em banho-maria, em temperatura entre $60^{\circ} \mathrm{C}$ e $80^{\circ} \mathrm{C}$ até solubilidade. Após resfriamento $20 \mu \mathrm{L}$ foram aplicados sobre os discos de papel.

As placas foram incubadas em estufa bacteriológica à $36{ }^{\circ} \mathrm{C}\left( \pm 1{ }^{\circ} \mathrm{C}\right)$ por um período de 24 horas. Realizou-se a leitura das placas pela medição do diâmetro dos halos de inibição com auxílio de paquímetro. As análises foram realizadas em triplicata, e os resultados expressos pela média das determinações.

\subsection{Determinação do pH}

A determinação do $\mathrm{pH}$ de cada sabonete foi realizada em triplicata através do método potenciométrico, utilizando pHmetro digital (Marca ION, modelo pH B500), previamente calibrado. Procedeu-se leitura do pH após a diluição das amostras, em temperatura média de $21^{\circ} \mathrm{C}$. A determinação foi realizada em triplicata, e os resultados expressos pela média.

\section{Resultados e Discussão}

A escolha dos sabonetes antibacterianos utilizados no estudo se deu devido a disponibilidade de serem adquiridos no comércio e por serem os mais utilizados pela população no cotidiano. Como as formulações dos sabonetes estudados são diferentes, a Tabela 1 apresenta alguns dos insumos presentes na composição desses produtos conforme informações contidas na embalagem, além da função que cada um desses insumos desempenha na formulação. 
Tabela 1 - Composição dos sabonetes antibacterianos avaliados e suas respectivas funções.

\begin{tabular}{|c|c|c|c|c|c|}
\hline FUNÇÕES & $\mathbf{A}$ & $\mathbf{B}$ & $\mathbf{C}$ & $\mathbf{D}$ & $\mathbf{E}$ \\
\hline Veículo & Água & Água & Água & Água & Água \\
\hline Cor & Corante & - & - & Corante & - \\
\hline Antimicrobiano & - & - & - & - & Triclosan \\
\hline $\begin{array}{c}\text { Umectante/ } \\
\text { Solvente }\end{array}$ & - & Glicerina & Glicerina & Glicerina & - \\
\hline Quelante & - & $\begin{array}{c}\text { EDTA } \\
\text { tetrassódico }\end{array}$ & $\begin{array}{c}\text { EDTA } \\
\text { tetrassódico }\end{array}$ & $\begin{array}{c}\text { EDTA } \\
\text { tetrassódico }\end{array}$ & EDTA \\
\hline Corretor de pH & - & - & - & - & $\begin{array}{l}\text { Hidróxido de } \\
\text { sódio } \\
\text { Ácido cítrico }\end{array}$ \\
\hline Espessante & $\begin{array}{l}\text { Cloreto de } \\
\text { sódio }\end{array}$ & - & Cloreto de sódio & Cloreto de sódio & Cloreto de sódio \\
\hline Conservante & Fenoxietanol & - & $\begin{array}{c}\text { DMDM } \\
\text { hidantoína }\end{array}$ & $\begin{array}{c}\text { DMDM } \\
\text { hidantoína }\end{array}$ & - \\
\hline $\begin{array}{l}\text { Estabilizante/ } \\
\text { Opacificante }\end{array}$ & - & - & Dióxido de titânio & - & Dióxido de titãnio \\
\hline Surfactante aniônico & Laurato de sódio & - & Laurato de sódio & Laurato de sódio & - \\
\hline Detergente & $\begin{array}{l}\text { Palmitato de } \\
\text { sódio }\end{array}$ & - & $\begin{array}{l}\text { Palmitato de } \\
\text { sódio }\end{array}$ & $\begin{array}{l}\text { Palmitato de } \\
\text { sódio }\end{array}$ & - \\
\hline $\begin{array}{c}\text { Tensoativo } \\
\text { aniônico }\end{array}$ & Oleato de sódio & - & $\begin{array}{c}\text { Estearato de } \\
\text { sódio }\end{array}$ & $\begin{array}{c}\text { Estearato de } \\
\text { sódio }\end{array}$ & - \\
\hline Fragrância & Cumarina & $\begin{array}{c}\text { Butilfenil } \\
\text { metilpropional, } \\
\text { Cumarina }\end{array}$ & $\begin{array}{c}\text { Butilfenil } \\
\text { metilpropional }\end{array}$ & $\begin{array}{c}\text { Butilfenil } \\
\text { metilpropional }\end{array}$ & $\begin{array}{c}\text { Butilfenil } \\
\text { metilpropional, } \\
\text { Cumarina, Alfa - } \\
\text { isometilolona }\end{array}$ \\
\hline Óleos essenciais & Linalol & Linalol & Citronelol & - & $\begin{array}{c}\text { Citronelol, } \\
\text { Geraniol, } \\
\text { Linalol }\end{array}$ \\
\hline
\end{tabular}

Fonte: Autores. Nota: (-) não contém.

Ao analisar os insumos observou-se que apenas a marca E apresentava o princípio ativo antibacteriano (Triclosan) junto aos demais ingredientes do produto disponibilizados na própria embalagem. As demais marcas não apresentavam em seu rótulo a substância ativa presente na formulação. Por ser um produto destinado para a prevenção ou até mesmo eliminação de microrganismos, em conformidade com as deliberações da ANVISA, todas as marcas deveriam disponibilizar em seu rótulo a substância ativa presente, sendo esta considerada uma informação obrigatória para cosméticos de grau 2 (Brasil, 2015). Assim, entrou-se em contato com as demais empresas para verificar quais seriam as substâncias ativas destes sabonetes (Tabela 2). 
Tabela 2 - Informações fornecidas pelo fabricante e/ou contidas nos rótulos dos sabonetes antibacterianos testados.

\begin{tabular}{cccc}
\hline Marca & $\begin{array}{c}\text { Substância } \\
\text { Ativa }\end{array}$ & Frases de marketing & $\begin{array}{c}\text { Bactérias sensíveis ao sabonete de acordo com } \\
\text { o fabricante }\end{array}$ \\
\hline A & Triclocarban & Elimina $99,9 \%$ das bactérias & E. coli \\
B & - & Ausente & - \\
& Triclocarban & 10 vezes mais proteção & E. coli e K. pneumoniae \\
D & Triclocarban & $100 \%$ melhor proteção & - \\
E & Triclosan & Ausente & \\
\hline
\end{tabular}

Fonte: Autores. Nota: (-) informação não encontrada/ não fornecida.

É possível verificar que dentre as marcas de sabonetes avaliados, o triclocarban se mostrou o princípio ativo antibacteriano mais frequente. Para o produto B não foi possível encontrar nenhuma informação fornecida pelo fabricante em relação a sua substância ativa, porém suspeita-se que sua atividade antimicrobiana possa estar relacionada também ao óleo essencial linalol presente na formulação, o qual já foi comprovado apresentar essa propriedade (Camargo \& Vasconcelos, 2014).

O componente triclosan, além de propriedades antibacterianas possui atividade antiviral e antifúngica. Em menores concentrações possui efeito bacteriostático e em elevadas concentrações é bactericida. Este componente geralmente possui maior eficácia contra organismos Gram-positivos, incluindo $S$. aureus, porém é particularmente ineficaz contra $P$. aeruginosa (Martins, 2014).

O triclocarban é utilizado principalmente em sabonetes antimicrobianos e em desodorizantes. Este atua contra bactérias Gram-positivas, porém é menos ativo contra bactérias Gram-negativas e fungos. Segundo alguns estudos, o triclocarban é permanece sobre a pele após aplicação, e pode ser absorvido após uma única exposição tópica (Martins, 2014).

Em outros estudos realizados utilizando sabonetes antibacterianos, contendo o triclosan ou o triclocarban, observou-se que atividade antibacteriana é diretamente proporcional a concentração de ativo presente em cada produto, porém é comum a associação de dois princípios ativos (Silva \& Souza, 2015).

Em uma pesquisa realizada com sabonetes antibacterianos contendo diferentes concentrações do ativo triclosan e triclocarban, Costa et al. (2018) afirmou que "existe uma diferença notória entre os halos de inibição de E. coli e $S$. aureus, demonstrando que a ação dos sabonetes foi mais efetiva frente a cepa de $S$. aureus".

A análise do pH de uma formulação é de relevante importância, pois o pH de um produto deve manter-se igual durante todo o seu prazo de validade, uma vez que a alteração do pH pode significar alteração da estabilidade da formulação e levar o produto a causar sensibilidade. Sendo assim, o pH do produto é importante não somente para evitar irritações e exposição da pele a agentes agressores, principalmente bactérias (Blaak \& Peter, 2018), mas para predizer a estabilidade química (Hoscheid, et al., 2017). Segundo a legislação brasileira, o pH dos sabonetes em barra deve ser em torno de 10,4, não ultrapassando 11,5 (Anvisa, 2008). Os resultados obtidos no presente estudo encontram-se na Tabela 3. 
Tabela 3 - Resultados obtidos através da determinação do pH.

\begin{tabular}{cc}
\hline Produto & pH \\
\hline A & $9,65 \pm 0,05$ \\
B & $9,63 \pm 0,04$ \\
C & $9,57 \pm 0,05$ \\
D & $9,66 \pm 0,03$ \\
E & $10,14 \pm 0,01$ \\
\hline
\end{tabular}

Nota: Valores expressos pela média $(\mathrm{n}=3) \pm$ desvio padrão. Fonte: Autores.

Os valores de $\mathrm{pH}$ obtidos variaram de 9,57 (produto C) a 10,14 (produto E). Nenhuma das marcas analisadas apresentou em sua embalagem informações em relação ao pH. De acordo com a legislação, apenas o pH da marca E encontrouse próximo ao recomendado. A outras marcas apresentaram $\mathrm{pH}$ inferior ao preconizado pela Anvisa.

Segundo Blaak \& Peter (2018), o pH da pele é naturalmente ácido, entre 4,0 e 6,0 e a alcalinidade poderia causar irritação cutânea. Assim as indústrias vêm buscando sabonetes com pH mais próximo ao da pele, a fim de diminuir a irritação cutânea e evitar problemas dermatológicos, porém os sabonetes em barra não são os mais adequados, devido a reação com soda caústica no processo de fabricação eles se caracterizam-se pelo $\mathrm{pH}$ alcalino, sendo portanto, mais fácil o ajuste de pH em sabonetes líquidos (Draelos, 1999). Nesse contexto, ressalta-se que em casos de irritações o sabonete em barra não é o mais recomendado e sim o líquido devido ao pH do mesmo ser próximo ao pH da pele (Araújo, Giudici \& Sousa, 2019).

A eficácia dos sabonetes antibacterianos foi comparada usando o método de difusão em Ágar, onde foram utilizadas as culturas puras das bactérias S. pyogenes, K. pneumoniae, P. aeruginosa, S. epidermidis, S. aureus e E. coli.

Na Figura 1, é possível visualizar os resultados obtidos no teste de difusão em Agar e o respectivo desvio padrão de cada produto testado. 
Figura 1 - Média dos halos de inibição de crescimento dos microrganismos e respectivo desvio padrão.

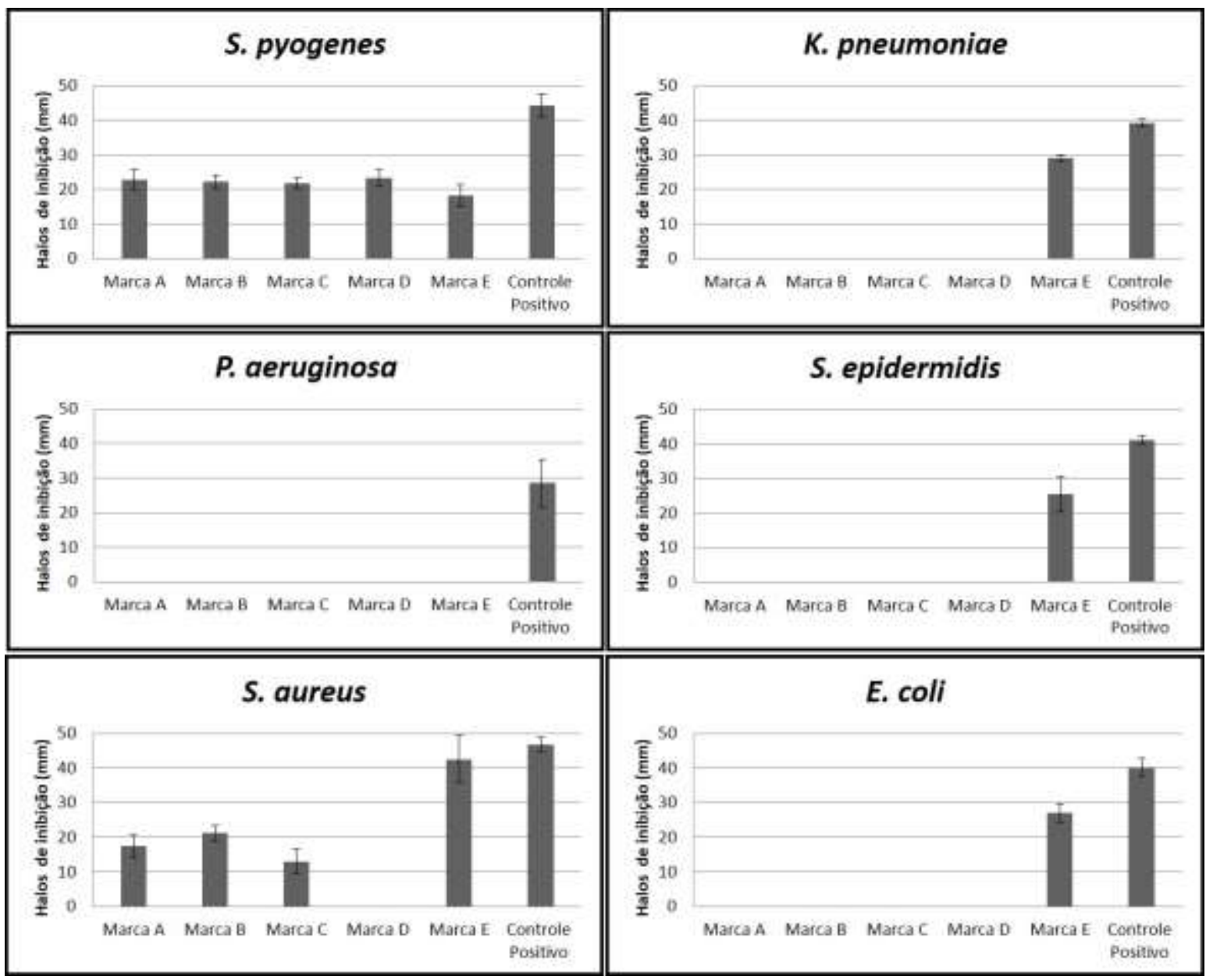

Fonte: Autores. Nota: Os dados foram expressos como a média do halo de inibição do crescimento \pm o desvio padrão de três experimentos independentes.

De acordo com a Figura podemos observar que houve uma grande variação nos resultados obtidos. Na concentração de $100 \mathrm{mg} / \mathrm{mL}$, os sabonetes da marca A, B e C apresentaram zona de inibição de crescimento somente para as bactérias $S$. pyogenes (22,7 mm, 22,2 mm e 21,7 mm, respectivamente) e $S$. aureus $(17,3 \mathrm{~mm}, 21,2 \mathrm{~mm}$ e $13,0 \mathrm{~mm}$, respectivamente). O sabonete D mostrou-se efetivo apenas para $S$. pyogenes $(23,3 \mathrm{~mm})$. Já o sabonete da marca E foi o único que mostrou-se efetivo para a maioria dos microrganismos testados, exceto frente a P. aeruginosa, inibindo o crescimento de $S$. aureus $(42,5$ $\mathrm{mm})$, K. pneumoniae $(29,0 \mathrm{~mm})$, E. coli $(27,0 \mathrm{~mm})$, S. epidermidis $(25,5 \mathrm{~mm})$ e $S$. pyogenes $(18,1 \mathrm{~mm})$.

O controle positivo formou halo de inibição para todos os microrganismos testados, obtendo-se para S. pyogenes 44,2 $\mathrm{mm}, K$. pneumoniae 39,2 mm, P. aeruginosa 28,5 mm, S. epidermidis 41,0 mm, S. 42,0 mm e para E. coli 40,2 mm. Portanto, as bactérias mais sensíveis aos diversos sabonetes utilizados foram S. pyogenes, seguido de S. aureus. Os resultados de sensibilidade e resistência das bactérias baseiam-se no tamanho dos halos de inibição de crescimento do antibiótico utilizado como controle positivo.

A bactéria $P$. aeruginosa, foi a mais resistente aos sabonetes, ou seja, nenhum sabonete foi capaz de apresentar zona de inibição de crescimento para este microrganismo. A $P$. aeruginosa causa infecções com maior frequência em pacientes hospitalizados imunodeprimidos, principalmente as infecções consequentes de processos cirúrgicos ou queimaduras resultando em bacteremias severas, apresentando riscos a crianças e idosos. Esta espécie é naturalmente resistente a vários tipos de 
antibióticos, pela presença de uma membrana dupla, rica em lipopolissacarídeo, envolvendo a célula bacteriana, que impede a entrada de determinados antibióticos na célula (Mielko et al., 2019).

No homem normalmente são encontrados de 0 a $2 \%$ de $P$. aeruginosa na pele, 0 a $3 \%$ na mucosa nasal, e 0 a $6 \%$, pode estar presente na axila e região perianal. Geralmente, habitam a água, os vegetais e o solo, portanto possui grandes fontes de contaminação (Araújo, 2013).

As bactérias $S$. aureus e $S$. pyogenes apresentaram menor resistência aos produtos testados, estas bactérias fazem parte do grupo de cocos Gram-positivos presentes na microbiota humana e frequentemente encontradas em pessoas sadias, porém, caso as barreiras naturais do corpo humano, isto é, pele e mucosas, estejam comprometidas por algum trauma ou cirurgia estes microrganismos podem se alojar no tecido e provocar doenças que vão desde simples infecções de pele, até problemas mais graves, como pneumonia, meningite e faringite (Furquim \& Medina, 2015).

Em comparação com estudos realizados sobre a mesma temática e utilizando o método de disco-difusão, observou-se resultados semelhantes ao presente estudo. A bactéria Gram-negativa E. coli foi menos sensível a ação dos sabonetes do que a bactéria Gram-positiva $S$. aureus, o que ocorreu provavelmente devido a diferença entre a parede celular de ambas as bactérias (Soares, 2013).

Marisco, Salgado e Santos (2018) realizaram um estudo com a mesma marca de sabonete (marca A) e observaram que este inibiu apenas bactérias Gram-positivas, sendo sua ação quase imperceptível sobre a S. epidermidis, resultado semelhante ao que foi encontrado neste estudo onde não foi possível observar halo de inibição para S. epidermidis, apenas para $S$. aureus e S. pyogenes.

Em relação ao triclocarban, o qual segundo a literatura apresenta menor atividade contra bactérias Gram-negativas, foi possível observar neste estudo que os produtos contendo este ativo, sendo as marcas A, C e D, não apresentaram nenhuma atividade contra este grupo de bactérias (Costa, et al., 2018).

Estudos apontam que a limpeza das mãos com sabonete antibacteriano pode ser inofensivo ou até mesmo saudável, porém o triclosan pode trazer riscos para a saúde, por ser altamente bactericida e também causar resistência bacteriana (Costa, et al., 2018). Diariamente são descartados em canalizações domésticas produtos contendo o triclosan e o triclocarban, estas substâncias permanecem no meio ambiente e sofrem biotransformação, aumentando a sua toxicidade, causando danos em ecossistemas marinhos e terrestres (Tiburtius \& Scheffer, 2014). A exposição do ser humano ao triclosan pode resultar em prejuízos à saúde, estudos toxicológicos sugerem que este ativo pode afetar a função endócrina, a homeostase do hormônio tireoidiano a resistência a antibióticose também danos à integridade da pele (Yueh \& Tukey, 2016).

O FDA (Food and Drug Administration) tem por objetivo proteger a saúde pública, em relação à segurança e eficácia de produtos, com isto, há vários anos vem avaliando os riscos e benefícios dos sabonetes antibacterianos. Em 2013, a FDA emitiu recomendações novas para se definir a segurança e a eficácia destes cosméticos. A nova legislação exige que os fabricantes de sabonetes antibacterianos provem que os mesmos são seguros para o uso diário sob longo prazo, e que apresentam maior eficácia em relação à água e o sabão comum na remoção de germes, bactérias e vírus, bem como para a prevenção de doenças e propagação de certas infecções (Rangel, 2007). As empresas que não cumprirem estas exigências terão que reformular seus produtos, retirando as substâncias ativas destes para que possam continuar comercializando-os (Martins, 2014).

Nos Estados Unidos foram proibidos 19 compostos usados nos produtos antibacterianos (Chattopadhyay, 2017). Também, nos EUA, já proibiu-se o uso de sabonetes antibacterianos devido à estes não terem se mostrado mais efetivos em comparação aos tradicionais, além disso eles podem trazer danos para a saúde, como problemas relacionados ao sistema imunológico, propiciando a resistência bacteriana (NPR, 2016). 
A Comissão Europeia também reprovou a utilização de triclosan e triclocarban em produtos cosméticos desde 2016. Na Coréia esses produtos são proibidos, e países como Canadá e Japão também restringem o conteúdo de triclocarban em cosméticos (Chattopadhyay, 2017).

Pode-se observar através dos resultados obtidos que praticamente todos os sabonetes testados apresentaram pouco ou nenhum efeito frente aos microrganismos avaliados, portanto os rótulos destes produtos deveriam ser reajustados. Além disso, existe uma ampla tentativa de conscientização da população para o uso prudente de antimicrobianos, e a presença desses ativos em produtos de venda livre, representa uma grande ameaça impactando diretamente no desenvolvimento de resistência bacteriana.

\section{Considerações Finais}

A partir das análises realizadas neste estudo, foi possível comparar as informações fornecidas nos rótulos dos produtos, o pH e a atividade antibacteriana de diferentes marcas de sabonetes. Em relação ao pH, observou-se que os mesmos encontram-se com valores próximos uns aos outros, porém não estão de acordo com os padrões estabelecidos pela Anvisa.

Entre as 5 diferentes marcas de sabonetes antibacterianos analisados, a marca E apresentou melhores resultados em relação a sua atividade contra as bactérias testadas, enquanto as demais mostraram-se pouco efetivos, portanto seus rótulos deveriam ser reformulados. Dentre as bactérias testadas, é possível concluir que $S$. aureus e $S$. pyogenes, apresentaram-se mais sensíveis aos sabonetes, enquanto isso, a P. aeruginosa, apresentou maior resistência aos produtos.

Tendo em vista a polêmica gerada diante de sabonetes antissépticos e suas atividades antibacterianas questionadas, cabe a Agência Regulamentadora rever o uso desses produtos, viabilizando o uso seguro pela população.

Conforme já descrito na literatura, apesar do triclosan e o triclocarban estarem presentes na maioria das formulações de sabonetes antibacterianos, visto que não há estudos conclusivos sobre a ação antibacteriana e toxicidade, os mesmos podem ser nocivos à saúde humana e meio ambiente. Assim, sugerem-se estudos adicionais o potencial bactericida e toxicológico, bem como uma investigação profunda sobre os princípios ativos e concentrações utilizados nestas formulações.

\section{Referências}

Andrade, N. J. (2008). Higiene na indústria de alimentos: avaliação e controle da adesão e formação de biofilmes bacterianos. Editora Varela.

Anvisa. (2007). Guia de Controle de Qualidade de Produtos Cosméticos. Uma Abordagem sobre os Ensaios Físicos e Químicos. Agência Nacional de Vigilância Sanitária - ANVISA.

Anvisa (2008). Guia de Controle de Qualidade de Produtos Cosméticos: uma abordagem sobre os Ensaios Físicos e Químicos. Agência Nacional de Vigilância Sanitária - ANVISA.

Anvisa (2009). Segurança do Paciente em Serviços de Saúde: Higienização das Mãos. Brasília: Agência Nacional de Vigilância Sanitária - ANVISA.

Araújo, A. C. F. (2013). Avaliação da qualidade microbiana de sabonetes comercializados em feiras de artesanato de Brasília. 2013 . 72 f. Dissertação (Mestrado em Ciências da Saúde). Brasília: Universidade de Brasília.

Araújo, F. O., Giudici, R., \& Sousa, J. J. M. S. (2019). Emprego de insumo nanobiotecnológico natural em uma formulação farmacêutica. Research, Society and Development, 9,2 .

Brasil. (2015). Agência Nacional de Vigilância Sanitária. Resoluçãoda Diretoria Colegiada $n^{\circ}$ 07, de 10 de fevereiro de 2015 . Dispõe sobre os requisitos técnicos para a regularização de produtos de higiene pessoal, cosméticos e perfumes e dá outras providências, Brasília: Agência Nacional de Vigilância Sanitária - ANVISA.

Camargo, S. B., \& Vasconcelos, D. F. S. A. (2014). Atividades biológicas de Linalol: conceitos atuais e possibilidades futuras deste monoterpeno. Revista de Ciências Médicas e Biológicas, 13, 3, 381-387.

Chattopadhyay, D. (2017). Antibacterial Consumer Products: How Reliable Are They? Resonance, 22, $761-767$.

Costa, A. C., Leite, H. W. S., Santos, L. C., Amorim, M. S., Silva, K. M. R. \& Araújo, E. T. H. (2018). Efeitos antimicrobianos, in vitro, de sabonetes líquidos contendo Triclosan frente cepas de Escherichia coli e Staphylococcus aureus. Revista Prevenção de Infecção e Saúde, 4, 1-10.

Draelos, Z. D. (1999). Cosméticos em dermatologia. Rio de Janeiro: Revinter. 
Research, Society and Development, v. 10, n. 2, e20310212241, 2021

(CC BY 4.0) | ISSN 2525-3409 | DOI: http://dx.doi.org/10.33448/rsd-v10i2.12241

Draelos, Z. D. (2018). The science behind skin care: cleansers. Journal of Cosmetic Dermatology, 17 (1), 8-14.

Eucerin. (2016). Manto ácido cutâneo. Retrieved from https://www.eucerin.pt/sobre-apele/conhecimentos-basicos-da-pele/skins-ph

Freire, V. A, Silva M. V. F., Medeiros M. A. \& Marsiglia W. I. M. L. (2012). Análise físico-química de sabonetes em barra de baixo custo comercial. Revista ENECT, 1-8.

Furquim, F. C., \& Medinab, L. T. (2015). Identificação de Staphylococcus e Enterobactérias em Brinquedos de uma Creche em Mato Grosso, Brasil. UNOPAR Cient Ciênc Biol Saúde, 17(3),181-188.

Hoscheid, J., Outuki, P. M., Kleinubing, S. A., Goes, P. R. N., Lima, M. M. S., Cuman, R. K. N. \& Cardoso, M. L. C. (2017). Pterodon pubescens oil nanoemulsions: physiochemical and microbiological characterization and in vivo anti-inflammatory efficacy studies. Brazilian Journal of Pharmacognosy, 27, $375-383$.

Pessoa Junior, E. F. P. (2011). Caracterização físico-química de sabonetes antibacterianos de diferentes marcas disponíveis no mercado brasileiro. 2011. 16f. Trabalho de Conclusão de Curso (Graduação em Farmácia). Campina Grande: Universidade Estadual da Paraíba.

Leonardi, G. R., Gaspar, L. R. \& Campos, P. M. B. G. M. (2002). Estudo da variação do pH da pele humana exposta à formulação cosmética acrescida ou não das vitaminas a, e ou de ceramida, por metodologia não invasiva. Anais Brasileiros de Dermatologia, 77(5), 563-569.

Leonardi, G. R. \& Maia Campos, P. M. B. G. (2001). Estabilidades de formulações cosméticas. International Journal of Pharmaceutical Compounding, 3(4), 154-156.

Marisco, G., Salgado, V. \& Santos, R. (2019). Eficiência de sabonetes comerciais antissépticos e comuns contra bactérias patogênicas e sua relação com a saúde e meio ambiente. Interfaces Científicas - Saúde e Ambiente, 7(3), 33-48.

Martins, C. G. D. (2014). Sabonetes antibacterianos: eficácia e segurança. 2014. 33 f. Dissertação (Mestrado Integrado em Ciências Farmacêuticas). Coimbra: Universidade de Coimbra.

Mielko, K. A., Jablonski, S. J., Milczewska, J., Sands, D., Lukaszewicz, M., \& Mlynarz, P. (2019). Metabolomic studies of Pseudomonas aeruginosa. World Journal of Microbiology \& Biotechnology, 35(11), 178.

NCCLS (2003). Performance Standards for Antimicrobial Disk Susceptibility Tests, Approved Standard-Eighth Edition. Pennsylvania: NCCLS.

NPR. FDA Bans 19 Chemicals Used In Antibacterial Soaps. npr.org/sections/health-shots/2016/09/02/492394717/fda-bans-19-chemicals-used-inantibacterialsoaps

Odonkor, S. T., Kitcher, J., Okyere, M., \& Mahami, T. (2019). Self-assessment of hygiene practices towards predictive and preventive medicine intervention: a case study of university students in ghana. Biomed research international, 2019.

Rangel, G. W. (2017). Say Goodbye to Antibacterial Soaps: Why the FDA is banning a household item. SITN, Boston: SITN.

Silva, P. S. \& Souza, L. B. G. (2015). Avaliação da atividade antibacteriana in vitro de sabonetes antissépticos com diferentes concentrações de triclosan. Encontro Internacional de Produção Científica UniCesumar, 9, 4-8.

Soares, M. P. M. (2013). Avaliação da eficiência de sabonetes com triclosan sobre suspensões bacterianas de Escherichia coli e Staphylococcus aureus aplicadas sobre a superfície das mãos de voluntários. 2013. 82 f. Dissertação (Mestrado em Ciência de Alimentos, Tecnologia de Alimentos, Engenharia de Alimentos). Viçosa: Universidade Federal de Viçosa.

Tiburtius, E. R. L. \& Scheffer, E. W. O. (2014). Triclosan: Destino no Meio Ambiente e Perspectivas no Tratamento de Águas de Abastecimento Público. Revista Virtual de Química, 6(6), 1144-1159.

Two, A. M., Nakatsuji, T., Kotol, P. F., Arvanitidou, E., Du-Thumm, L., Hata, T. R., \& Gallo, R. L. (2016). The Cutaneous Microbiome and Aspects of Skin Antimicrobial Defense System Resist Acute Treatment with Topical Skin Cleansers. Journal of Investigative Dermatology, 136 (10), $1950-1954$.

Yueh, M. F., \& Tukey, R. H. (2016). Triclosan: a widespread environmental toxicant with many biological effects. Annual Review of Pharmacology and Toxicology 